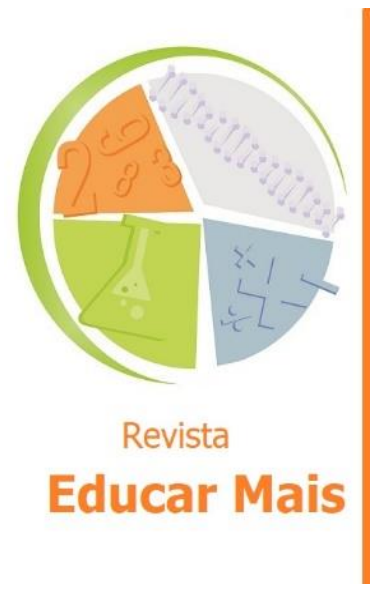

\section{Expectativa versus realidade: experiências, percepções e desempenhos discentes frente ao ensino} remoto

\author{
Expectations versus reality: experiences, perceptions and student \\ performance in relation to remote teaching
}
Expectativas versus realidad: experiencias, percepciones $y$ rendimiento estudiantil frente a la enseñanza remota Valesca Brasil Iralaㄹ; Maria Regina de Oliveira Casartelli²; Leandro Blass ${ }^{3}$;
Cristiano Saldanha da Silva ${ }^{4}$

\title{
RESUMO
}

Esta pesquisa busca descrever dois macro-construtos: a autoeficácia percebida (ao início e ao final do primeiro semestre remoto) e as expectativas (as esperadas ao início do semestre e as observadas ao final do mesmo semestre). Para tanto, foram analisados 135 estudantes que participaram de ambas as etapas de coleta de dados, em uma instituição pública brasileira de ensino superior, a partir da observação de médias e medianas e pelo Teste de Wilcoxon para grupos pareados. Também foram observadas as possíveis diferenças entre estudantes ingressantes e veteranos em termos de desempenho acadêmico. Ainda, estabeleceu-se um comparativo sobre o tempo de dedicação à Internet dos alunos para atividades acadêmicas e não-acadêmicas, antes e depois da experiência remota. Os indicadores de expectativas mostraram-se com maiores diferenças do que os de autoeficácia ao longo do semestre. Ainda, o tempo de uso de internet para atividades nãoacadêmicas não sofreu mudanças, mas para as atividades acadêmicas houve alteração. Também, os alunos veteranos apresentaram resultados globais mais satisfatórios do que os ingressantes, o que reforça a necessidade de maior atenção institucional a esse segmento.

Palavras-chave: Ensino remoto; Análise quantitativa; Teste de Wilcoxon; Desempenho acadêmico; Ensino superior.

\begin{abstract}
This research seeks to identify two macro-constructs: perceived self-efficacy (at the beginning and end of the first remote semester) and expectations (expected at the beginning of the semester and those observed at the end of the same semester). To this purpose, 135 students participated in both stages of data collection in a Brazilian public institution of higher education, based on the observation of means and medians and using the Wilcoxon test for paired groups. Freshman and veteran students were different in terms of academic performance. In addition, the time spent on the Internet by students for academics activities was different before and after the remote experience, but for non-academics was not. The expectations indicators show bigger differences than the self-efficacy indicators throughout the semester. Still, the time of internet use for
\end{abstract}

\footnotetext{
${ }^{1}$ Professora Associada, docente do Mestrado Acadêmico em Ensino da Universidade Federal do Pampa (UNIPAMPA) e Líder do Grupo de Pesquisa sobre Aprendizagens, Metodologias e Avaliação (GAMA), Bagé/RS - Brasil. E-mail: valescairala@unipampa.edu.br

2 Professora Associada, docente da área de Química da Universidade Federal do Pampa (UNIPAMPA), Bagé/RS - Brasil. E-mail: mariacasartelli@unipampa.edu.br

${ }^{3}$ Professor Adjunto, docente da área de Matemática da Universidade Federal do Pampa (UNIPAMPA) e membro do Grupo de Pesquisa sobre Aprendizagens, Metodologias e Avaliação (GAMA), Bagé/RS - Brasil. E-mail: leandroblass@unipampa.edu.br

${ }^{4}$ Graduando da Licenciatura em Matemática da Universidade Federal do Pampa (UNIPAMPA), Bagé/RS - Brasil. E-mail: cristianosilva.aluno@unipampa.edu.br
} 
non-academics activities did not change, but for academics there was change. Also, veteran students have more satisfactory overall results than freshmen, what reinforces the need for greater institutional attention to this follow-up.

Keywords: Remote teaching, Quantitative analysis, Wilcoxon test; Academic performance; Higher Education.

\section{RESUMEN}

Esta investigación busca describir dos macro-constructos: la autoeficacia percibida (al inicio y al final del primer semestre remoto) y las expectativas (esperadas al inicio del semestre y las observadas al final del mismo semestre). Para ello, 135 estudiantes que participaron en ambas etapas de recolección de datos fueron analizados en una institución pública brasileña de educación superior, con base en la observación de medias y medianas y utilizando la prueba de Wilcoxon para grupos pareados. También se observaron posibles diferencias entre los estudiantes de primer año y los veteranos en términos de rendimiento académico. Aún así, se estableció una comparación sobre el tiempo de dedicación a Internet de los estudiantes para actividades académicas y no académicas, antes y después de la experiencia remota. Los indicadores de expectativas mostraron mayores diferencias que la autoeficacia a lo largo del semestre. Aún así, el tiempo de uso de Internet para actividades no académicas no cambió, pero para las actividades académicas sí cambió. Además, los estudiantes veteranos obtuvieron resultados generales más satisfactorios que los de primer año, lo que refuerza la necesidad de una mayor atención institucional a este seguimiento.

Palabras clave: Enseñanza remota; Análisis cuantitativo; Test de Wilcoxon; Rendimiento académico; Educación Superior.

\section{CONSIDERAÇÕES INICIAIS}

A pandemia da COVID-19, longe de ser um problema estritamente epidemiológico (ARRUDA, 2020; PARDO KUKLINSKI; COBO, 2020), afetou inúmeras dimensões da vida humana e os mais diversos setores produtivos da sociedade, de maneira inédita na história mundial recente. De forma múltipla e complexa, foram surgindo inúmeras respostas aos desafios estabelecidos frente aos modelos de distanciamento social impostos e regulamentados em escala mundial para enfrentar a crise sanitária, em razão da expansão e gravidade da doença, com variadas conjunturas metodológicas e especificidades temporais de país para país, ao longo de todo o ano de 2020 e ainda durante o ano de 2021.

Efetivamente, foi apenas na segunda quinzena do mês de março de 2020 que o Brasil se deparou de forma latente com a problemática, embora houvesse uma portaria do Ministério da Saúde, assinada em 03 de fevereiro de 2020, a qual já declarava "emergência em saúde pública de importância nacional" (BRASIL, 2020a, p. 01). Nesse documento, alertava-se para a complexidade do evento, bem como a instalação de medidas urgentes de controle e contenção dos riscos de contágio. Por sua vez, o Ministério da Educação, apenas em 17 de março de 2020, emitiu uma primeira portaria para as instituições integrantes do sistema federal de ensino, na qual se autorizou "a substituição das aulas presenciais por aulas em meios digitais enquanto durar a situação de pandemia do Novo Coronavírus - COVID-19)" (BRASIL, 2020b, p. 39).

As respostas de cada instituição ao novo formato, o tempo até a implantação e a aceitação das comunidades acadêmicas frente às alternativas possíveis de enfrentamento ao cenário posto foram as mais variadas (NEVES; ASSIS; SABINO, 2021). Nesse sentido, consideramos necessário pontuar de maneira situada e não generalizante as condições e os efeitos produzidos frente às mudanças geradas, especialmente tomando como base os elementos que de alguma maneira afetam à condução 
do que optamos por chamar de cena didática, a partir do olhar de um de seus atores mais vulneráveis: os estudantes.

A cena didática, na visão que apresentamos, é definida aqui como o jogo das ações assumidas pelos atores institucionais em favor da aprendizagem formal, através de inúmeras estratégias que podem ou não se configurarem como o que tradicionalmente convencionou-se chamar de "aula", no modelo que se conhecia presencialmente. A cena didática é bem mais abrangente do que uma "aula", pois visa contemplar tanto a assincronicidade das tarefas realizadas tanto por docentes quanto por discentes (preparação, execução, correção, refacção, visionamentos, etc.) quanto à natureza do que está em jogo durante, por exemplo, um encontro síncrono, bem como o que dele possa ser esperado na perspectiva de cada ator. Esta pesquisa está situada no escopo do projeto de pesquisa "Aprendizagens Ativas e colaborativas: análise da percepção docente, do engajamento discente, da autorregulação e do processo avaliativo" (CAAE 31352620.2.0000.5323, na Plataforma Brasil) e inserida no Grupo de Pesquisa GAMA - Grupos sobre Aprendizagens, Metodologias e Avaliação (registrado no Diretório do CNPq) vinculado a uma universidade pública localizada em uma região periférica na região sul do Brasil, a qual instaurou o ensino remoto nas turmas de graduação a partir de setembro de 2020 (ou seja, com um hiato de seis meses em relação ao início do calendário acadêmico previsto inicialmente). Os dados foram coletados junto a alunos matriculados em disciplinas de docentes que, ou fazem parte do referido grupo de pesquisa, ou desenvolvem trabalhos voltados à pesquisa em educação em colaboração com membros do grupo.

O objetivo deste artigo é descrever duas macro-categorias analisadas durante a oferta do primeiro semestre de ensino remoto: a autoeficácia percebida (ao início e ao final do primeiro semestre remoto) e as expectativas (as esperadas ao início do semestre e as observadas ao final do semestre). Para tanto, foram analisadas 135 observações de estudantes que participaram de ambas as etapas da pesquisa, bem como foi realizado um mapeamento dos seus desempenhos nas disciplinas analisadas, além de alguns parâmetros observacionais, tais como a qualidade da Internet à disposição para as atividades remotas, tempo destinado às atividades acadêmicas e não-acadêmicas no uso da Internet, bem como a sua condição de estudante (se veterano ou ingressante). Na próxima seção, as macro-categorias foco da pesquisa serão descritas em detalhamento.

\section{CARACTERIZAÇÃO TEÓRICO-METODOLÓGICA}

Optamos por mobilizar nesta pesquisa o constructo da autoeficácia, difundido pela Teoria Social Cognitiva, do psicólogo canadense Albert Bandura. A autoeficácia é entendida como a "crença na capacidade de executar determinados tipos de desempenhos" (BANDURA, 2006, p. 30, tradução nossa), apresentando inevitavelmente um caráter antecipatório. Nesse sentido, compreende-se a fecundidade do construto para compreender como os estudantes se relacionavam com múltiplos aspectos relacionados às suas capacidades percebidas, as quais julgamos que poderiam impactar na qualidade de sua primeira experiência com o ensino remoto.

Bates a e Khasawneh (2007), ao pesquisarem a autoeficácia dos estudantes frente ao uso de ambientes online de aprendizagem, referem-se que a novidade de se deparar pela primeira vez com esse tipo de experiência gera avaliações naturais mais frequentes sobre as tarefas demandadas, sendo preditoras de comportamentos, níveis motivacionais, de desempenho e de estresse, por exemplo. Tais avaliações puderam ser amadurecidas no contexto analisado no seio de cada membro da comunidade acadêmica antes do início do semestre, dado o grande período de espera de seis 
meses até o início efetivo das aulas. Um indicador desse aspecto no âmbito coletivo eram os constantes questionamentos produzidos por múltiplos atores sociais à época: "Será que vai dar certo? Como será que vou dar conta?".

Assim, as perguntas criadas, associadas ao constructo da autoeficácia, iniciadas pela expressão "Sou capaz de..." se vinculavam a diversos aspectos, os quais, de fato, para um conjunto de estudantes (e mesmo docentes) eram total ou parcialmente novos (ou apresentavam outra regularidade e/ou tipos de experiência antes da pandemia), como, por exemplo, as estratégias utilizadas para interagir através de videoconferências, determinados usos das Tecnologias Digitais da Informação e Comunicação (TDIC), as formas de se relacionar com recursos multiformatos (como consumidores e/ou produtores de vídeos, por exemplo) e, principalmente, a capacidade pessoal de se adaptar ao ensino remoto, mesmo diante de fatores externos desfavoráveis, tais como ruídos, entre outros. Os seis indicadores de autoeficácia gerados são descritos a seguir:

- Gestão da Informação e do conhecimento (GIC) - 5 itens - este indicador englobava itens relacionados à capacidade de identificação de fontes confiáveis de informação na Internet, o uso de buscadores (acadêmicos e não acadêmicos), bases de dados e revistas especializadas, uso de redes sociais e fóruns especializados em temas acadêmicos.

- Estratégias de interação em videoconferência (EIV) - 4 itens - este indicador englobava itens relacionados à participação ativa em atividades acadêmicas por videoconferência (perguntas e comentários em aula), discriminando-a por uso de chat, câmera ligada, câmera desligada e apresentação oral de um trabalho de forma remota.

- Usos e Manejos Básicos de TDIC (UMB) - 8 itens - esse indicador se refere a itens como instalação de softwares, criação de contas em serviços Web, entendimento de tutoriais, conversão de arquivos, uso de repositórios de compartilhamento, necessidade de busca de ajuda para resolver problemas com dispositivos, uso de ambientes virtuais de aprendizagem e manipulação de planilhas.

- Usos e Manejos Avançados de TDIC (UMA) - 5 itens - esse indicador aponta itens como aprender a usar por si uma variedade de programas e aplicativos, aprender funções avançadas de programas, resolução por si mesmo de problemas de configuração, conexão e uso de alguma linguagem de programação para a realização de tarefas acadêmicas.

- Indicadores de relacionamento com recursos multiformato (CPA) - 4 itens - este indicador apontava para o uso de videoaulas, podcasts, videocasts, bem como para a capacidade de elaboração de informações de maneira visual e para a gravação e edição de vídeos para trabalhos acadêmicos.

- Indicadores pessoais de adaptação ao ensino remoto (PAER) - 2 itens - este indicador contemplava aspectos como capacidade de manutenção da concentração e também de adaptação às plataformas e ferramentas digitais.

No que diz respeito ao segundo macro-contructo, denominado "expectativas", buscou-se comparar a avaliação inicial - denominadas expectativas esperadas - através do questionário administrado nas primeiras semanas de aula, com os verbos das questões no tempo verbal "futuro" - e as expectativas observadas - através do questionário administrado nas últimas semanas de aula do primeiro semestre ofertado remotamente pela instituição, com os verbos das questões no tempo verbal "pretérito". O 
constructo de autoeficácia também foi avaliado em ambos os questionários; porém, sem nenhuma alteração linguística nas questões em ambos os instrumentos. Passamos a descrever os indicadores das expectativas:

- Expectativas cognitivas (EC) - 2 itens - neste indicador, buscou-se identificar as expectativas quanto à aquisição de conceitos (básicos e complexos), através do ensino remoto.

- Expectativas frente ao desempenho individual (EDI) - 3 itens - o indicador incide sobre as expectativas de desempenho, tanto em relação a notas quanto ao desenvolvimento de tarefas.

- Expectativas frente à socialização do conhecimento (ESC) - 3 itens - buscou-se identificar aspectos relacionados à interação em relação aos temas acadêmicos propostos, seja junto aos colegas, seja junto aos professores, no modelo remoto.

- Expectativas quanto ao engajamento com colegas (EEC) - 5 itens - neste indicador, enquadram-se as visões a respeito da possibilidade de ajudar e ser ajudado pelos pares no ensino remoto, especialmente com elementos de contraste às possibilidades do ensino presencial.

- Expectativas quanto à presença docente (EPD) - 2 itens - neste indicador, a ênfase é no suporte esperado pelos professores. Aqui, entendemos o conceito de presença docente no sentido de Vaughan, Cleveland-Innes e Garrison (2013, p. 2, tradução nossa), como o "esforço e a atividade em torno do design, facilitação e direção de processos cognitivos e sociais", de forma a buscar dar sentido profundo aos processos de aprendizagem.

- Expectativas autorregulatórias (EAR) - 6 itens - neste indicador, englobam-se diferentes elementos em torno às estratégias autorregulatórias assumidas pelos alunos, tais como as relacionadas aos prazos, investimento e organização do tempo, comprometimento e disposição para as tarefas. Estratégias autorregulatórias são definidas, de forma abrangente como os "processos, atividades ou procedimentos que englobam a gama de ações que os alunos podem realizar automática ou deliberadamente durante a aprendizagem" (LAWSON et al., 2019, p. 225, tradução nossa).

- Expectativas quanto à comparação do Ensino Remoto com o Presencial (CERP) - 6 itens - este indicador mobiliza comparações quanto ao esforço pessoal, tempo, processo avaliativo, aprendizagem, facilidade, etc., que o aluno é convidado a estabelecer ao comparar as duas modalidades.

- Expectativas ambientais (EAM) - 2 itens - neste indicador, o estudante é convidado a avaliar suas expectativas quanto ao ambiente externo, no que diz respeito à privacidade para o estudo e a existência de um local adequado para as tarefas acadêmicas.

Na seção seguinte, efetuaremos a descrição do delineamento metodológico da pesquisa e, na sequência, apresentaremos a síntese dos dados a partir da análise exploratória efetuada e dos diálogos teóricos empreendidos a partir de outras pesquisas com ênfase em aspectos de interesse similares aos aqui apresentados, com foco nas experiências e percepções dos estudantes universitários durante o período da pandemia. É importante mencionar que o conceito de percepção assumido é o de Ingold (2000), que entende a percepção no campo da ação. Já o conceito de 
experiência se nutre em Josso (2002), que a aponta como diferente da simples vivência, dado que só experienciamos aquilo que damos atenção consciente. Nesta pesquisa, voltamo-nos aos autorrelatos gerados pelos estudantes, a partir de suas crenças de autoeficácia e suas expectativas (esperadas e observadas) frente à primeira experiência como discentes de um modelo de ensino remoto.

\section{PANORAMA SOBRE OS ESTUDANTES ANALISADOS}

Estudantes do Ensino Superior, de forma geral, mesmo antes da pandemia, já estavam imersos e relativamente apropriados daquilo que se conhece como "cultura digital" (KUKLINSKI; COBO, 2020). Entretanto, não é evidente que os elementos que a constituem já estivessem plenamente incorporados à cultura institucional universitária dos cursos presenciais de graduação da instituição foco da análise. Nesse sentido, buscou-se conhecer aspectos gerais que 135 estudantes do Ensino Superior de uma universidade pública periférica apresentavam no início de sua primeira experiência com o ensino remoto e estabelecer um comparativo dessas experiências iniciais ao término de um semestre letivo, a partir da autoeficácia percebida e das expectativas (esperadas e observadas) sobre elementos considerados como centrais para o novo modelo de ensino (mas também para o desenvolvimento de competências acadêmicas de maneira geral, independente do ensino remoto emergencial).

A pesquisa foi conduzida entre os meses de setembro (início do semestre letivo) e dezembro de 2020 (final do semestre letivo), totalizando em torno de 15 semanas de distanciamento entre 0 período de respostas do primeiro para o segundo questionário, administrado através da plataforma Freeonlinesurveys, para cada uma das disciplinas as quais tivemos acesso para a aplicação da pesquisa, através da colaboração dos respectivos professores, que repassaram os questionários por e-mail ou através de ambientes virtuais de aprendizagem, tais como o Moodle ou Google Classroom aos respectivos estudantes.

Ao todo, estiveram envolvidos alunos matriculados em 12 disciplinas diferentes (Fundamentos de Inglês I, Cálculo I, Letramentos em Espanhol, Cálculo I, Instrumentação de Processos, Tópicos em Controle de Processos, Física III, Cálculo Numérico, Química Geral, Química, Instrumentação para o Ensino de Química III, Metodologia da Pesquisa para Educação Química e Fundamentos da Sociologia), de 14 diferentes cursos de graduação (Letras-Línguas Adicionais, Engenharia de Computação, Engenharia de Alimentos, Química, Física, Engenharia Química, Engenharia de Produção, Engenharia de Energia, Matemática, Curso Interdisciplinar em Ciência e Tecnologia, Agronomia, Curso Interdisciplinar em Ciência e Tecnologia de Alimentos, Nutrição e Ciências Humanas).

A diversidade de áreas e cursos tem o intuito de buscar representatividade de estudantes com diferentes formações para esta pesquisa que se apresenta como de caráter descritivo e exploratório (RAUEN, 2006), de cunho quantitativo (LEVIN; FOX; FORDE, 2012), e, a partir dela, buscar expandir, em pesquisas futuras com ênfase similar, para mais áreas não contempladas neste estudo inicial. Ao todo, $44 \%$ dos participantes eram ingressantes ( $\mathrm{N}=59)$ no ano de 2020 e $66 \%$ de veteranos - ou seja, do 2019 para trás $(\mathrm{N}=76) ; 32 \%$ do gênero masculino $(\mathrm{N}=44)$ e $68 \%$ do gênero feminino $(\mathrm{N}=91)$. É importante citar que os ingressantes não chegaram a cursar nenhuma aula desde o seu ingresso na instituição na modalidade presencial, apenas por meio do ensino remoto emergencial. 
É válido mencionar que o número de participantes foi restrito apenas aos estudantes que responderam a ambos os questionários, extraindo-se para o banco de dados efetivamente analisado aqueles que apenas responderam ao questionário inicial ou apenas ao final, ainda que tenham concordado em participar da pesquisa através do Termo de Consentimento Livre e Esclarecido (TCLE), pelo fato de que o escopo da pesquisa era o contraste entre o início e o final do primeiro semestre remoto. Os dados brutos anonimizados se encontram disponíveis em Irala et al. (2021a). Ao todo, o banco de dados comportou 128 variáveis das 135 observações e foi analisado em três plataformas distintas: o Google Sheets vinculado à conta de e-mail institucional, bem como os softwares livres RStudio (R CORE TEAM, 2021) e Jamovi (THE JAMOVI PROJECT, 2021).

Além dos questionários, também foram observadas as médias dos alunos ao término do semestre analisado, classificando qualitativamente, por convenção fixada pela presente pesquisa, tais desempenhos como "ótimo" (entre 9,0 e 10,0 - 39\%), "bom" (entre 7,5 e 8,9 - 36\%), "suficiente" (entre 6,0 a 7,4 - 19\%) e "insuficiente" (5,9 ou menos - 7\% dos respondentes). Comparativamente, observou-se que discentes do gênero masculino apresentaram maior frequência de desempenhos ótimos do que do gênero feminino, bem como alunos veteranos também apresentaram, de forma geral, maior frequência de desempenhos ótimos do que os ingressantes.

Em relação à qualidade de Internet para as atividades remotas, 51\% a consideraram "boa", 14\% como "muito boa", 29\% como "não muito boa", 4\% como "terrível" e $2 \%$ como "excelente". É válido mencionar que, entre os alunos que apresentavam conexão de Internet "excelente", nenhum deles atingiu desempenho "suficiente" ou "insuficiente". Desses, 67\% apresentaram "boa" conexão e 33\% a identificou como "ótima". Também no que diz respeito aos dispositivos utilizados para as atividades, observou-se um incremento do início do semestre para o final, pois ao início, 75,2\% afirmavam possuir laptop/notebook e, ao término, esse número aumentou para 82,7\%; 15,8\% afirmava possuir desktop, aumentando para $19,3 \%$ ao final; $72,5 \%$ afirmavam ao início possuir smartphone com conexão de Internet, aumentando para $80,7 \%$ ao final do semestre letivo).

Outro aspecto que julgávamos relevante mapear era se a quantidade de horas conectados à Internet em atividades não-acadêmicas e em atividades acadêmicas diferiria ao início e ao término do semestre. Foi criada uma escala de 6 níveis para avaliar este aspecto, no qual o nível 6 contemplava dez horas ou mais de conexão; o nível 5, entre 6 e menos de 10 horas de conexão; 0 nível 4, mais de quatro horas e menos de seis horas de conexão; o nível 3 entre duas e quatro horas de conexão; o nível 2, mais de uma hora e menos de duas horas de conexão e, o nível 1, uma hora ou menos de conexão. Esses dados serão apresentados no Quadro 1:

Quadro 1 - Tempo de conexão antes e depois

\begin{tabular}{|c|c|c|}
\hline Tempo de Conexão à Internet & Ingressantes & Veteranos \\
\hline Internet para fins não-acadêmicos (início) & 3.49 & 3.39 \\
\hline Internet para fins não- acadêmicos (final) & 3.47 & 3.16 \\
\hline Internet para fins acadêmicos (início) & 3.20 & 3.10 \\
\hline Internet para fins acadêmicos (final) & 3.56 & 3.45 \\
\hline Índice Final - Inicial (fins não-acadêmicos) & -0.02 & -0.23 \\
\hline Índice Final - Inicial (fins acadêmicos) & +0.36 & +0.35 \\
\hline
\end{tabular}

Fonte: Autoria Própria (2021) 
Observa-se, pelos dados do Quadro 1, que as médias oscilaram entre os níveis 3 (entre duas e quatro horas de conexão) e 4 (mais de quatro horas e menos de seis horas de conexão). Também, verificase que houve um decaimento leve na quantidade de horas dedicadas para fins não-acadêmicos (índice de -0.02 para ingressantes e -0.23 para veteranos) e um aumento para a quantidade de horas de Internet em atividades acadêmicas de forma similar entre ingressantes $(+0.36)$ e veteranos $(+0.35)$.

Pode-se aventar que o decaimento menor de horas para uso de Internet para fins não-acadêmicos entre os ingressantes se deve ao fato de que o grau de dificuldade das disciplinas de início de curso tende a ser menor que o das disciplinas mais avançadas. Ainda sobre essas questões, através do teste de Wilcoxon, que tem como princípio "avaliar se ocorreram modificações nos dados entre os dois momentos da avaliação" (MORENO; MORCILLO, 2020, p. 2), verificou-se que não há diferença estatística observada para o tempo de Internet para atividades não-acadêmicas nos dois momentos de coleta de dados no conjunto de todos os estudantes, mas há para o tempo de Internet para atividades acadêmicas, o que reforça os achados disponibilizados na Tabela 1, na qual se buscou apresentar possíveis comparações entre os grupos de ingressantes e veteranos.

Além disso, sendo mais jovens e, em grande maioria, recém oriundos do Ensino Médio, os estudantes ingressantes ainda estão em forte processo de adaptação à cultura universitária e, portanto, esse momento de chegada, que tem sido considerado um período crítico do processo formativo, merece especial atenção por parte das instituições (TINTO, 2012). Um dado que pode corroborar para esse achado é que a média dos desempenhos dos veteranos (Média=8,26; Desvio Padrão=1,64; $N=76$ ) foi também ligeiramente superior à média dos desempenhos dos ingressantes (Média=8,1; Desvio Padrão=1,68; $N=59$ ) nas disciplinas analisadas.

Os questionários de autorrelato foram criados dominantemente a partir do modelo de escala Likert (RAUEN, 2006) dos constructos que desejávamos avaliar, a autoeficácia e as expectativas, como já apontamos na seção anterior, a partir dos indicadores já descritos, além dos dados sociodemográficos que queríamos observar (idade, gênero, dispositivos, conexão, etc.). Cada indicador, por sua vez, apresentava um conjunto de itens específicos. Ao todo, foram 28 itens vinculados à autoeficácia percebida e 29 itens às expectativas. As proposições foram avaliadas pelas opções "(1) Discordo fortemente", "(2) Discordo", "(3) não concordo e nem discordo", "(4) Concordo" e "(5) Concordo fortemente", o que os configura como variáveis qualitativas ordinais.

A consistência interna de cada macro-constructo, na primeira (início do semestre) e na segunda aplicação da pesquisa (final do semestre) foi medida a partir de uma técnica intitulada Alfa de Cronbach, a qual tem sido amplamente usada para avaliar a confiabilidade de um questionário (CRONBACH, 1951). Os resultados foram os seguintes: Cronbach's a Autoeficácia inicial = 0.928; Cronbach's a Autoeficácia final $=0.931$; Cronbach's a Expectativa Esperada $=0.889$; Cronbach's a Expectativa Observada $=0.912$ (é importante mencionar que, dos 29 itens do macro-constructo Expectativas, dois deles apresentaram correlação negativa com os demais, ou seja, foram considerados possivelmente como itens reversos). Como os valores obtidos foram próximos de 1, a confiabilidade do instrumento pode ser considerada alta ou muito alta (SOUZA; ALEXANDRE; GUIRALDELLO, 2017). Feito esse detalhamento, passamos para a análise efetiva dos dados na seguinte seção. 


\section{AUTOEFICÁCIA PERCEBIDA E EXPECTATIVAS}

Dado o volume extenso de dados, decidimos trazer no corpo do texto de forma detalhada apenas os aspectos que julgamos apresentar base para uma discussão mais profunda para a compreensão do ensino remoto emergencial, optando por disponibilizar o detalhamento dos descritivos de todo o conjunto de dados em Irala et al. (2021b). Em primeiro lugar, é importante mencionar que as medidas de tendência central (LEVIN; FOX; FORDE, 2012) - médias e medianas - não apresentam diferenças significativas para a maioria dos itens avaliados no início e no final do semestre. Essas informações também são confirmadas pelo Teste de Wilcoxon (MORENO; MORCILLO, 2020), pelo qual se observou, a um nível de significância de 5\%, que apenas dois itens (de 28) vinculados à autoeficácia apresentaram diferenças estatisticamente significativas nos dois períodos (ou seja, em apenas $14,2 \%$ dos itens) e onze itens (de 29) apresentaram diferenças no que diz respeito às expectativas (ou seja, em 37,9\% dos itens). Isso corrobora com a ideia de que houve, ao término do semestre, em sua maioria, a manutenção da autoeficácia percebida inicialmente e que as expectativas esperadas não sofreram, em geral, grandes divergências em relação às expectativas observadas ao início do semestre.

Embora as medidas tenham sido bastante próximas nos dois momentos - inicial e final - com tendências globais mais positivas no segundo momento, observamos, assim como nos dados de desempenho e de tempo de Internet para fins acadêmicos e não-acadêmicos, que os alunos veteranos apresentaram resultados mais satisfatórios do que os ingressantes. 0 gráfico de barras (Figura 1) a seguir ilustra visualmente esses resultados gerais a partir das médias dos dois grupos:

Figura 1 - Comparativo de médias gerais por macro-construto e categoria de aluno

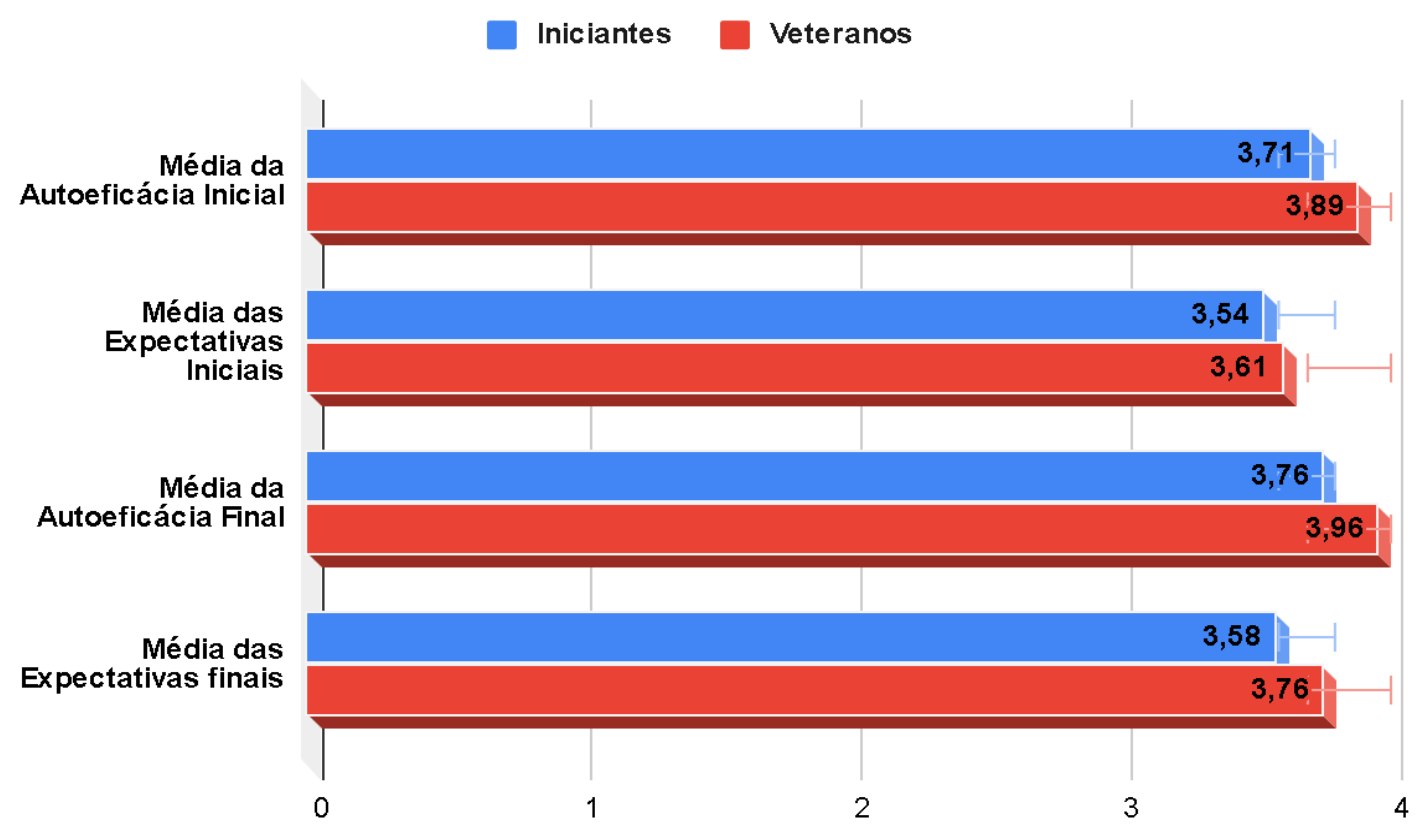

Fonte: Autoria Própria (2021)

Já no que diz respeito aos indicadores, chama-nos atenção alguns dados gerais que podem ser aperfeiçoados nas experiências acadêmicas dos alunos para além do momento pandêmico. No que diz respeito à gestão da informação e conhecimento, os alunos indicam, em geral, que se sentem mais capazes em utilizar buscadores gerais como o Google para fazer pesquisas sobre temas acadêmicos (Média no questionário final=4.6 e Mediana=5.0) do que bases de dados acadêmicas 
(ou mesmo o próprio Google Acadêmico) (Média no questionário final=4.1 e Mediana=4.0) ou a fazer pesquisas sobre temas acadêmicos em redes sociais, como o Facebook ou o Twitter (Média no questionário final=3.7 e Mediana=4.0), por exemplo.

Sobre o indicador de estratégias de interação em videoconferência, os estudantes foram inqueridos a apresentar suas percepções a respeito da capacidade de participação ativa em atividades acadêmicas. Nesse item, observamos um decaimento do questionário inicial para o final no que diz respeito à capacidade de efetuar perguntas e comentários com câmera ligada por parte dos alunos ingressantes (Média inicial= 3.5; Média final=2.9) e a mesma média nos dois questionários para os veteranos (Média=3.4). A média para a participação ativa com a câmera desligada também apresentou decaimento para os ingressantes e se manteve estável para os veteranos (média inicial dos ingressantes $=4.0$; média final dos ingressantes=3.8; média inicial e final dos veteranos $=4.1$ ). $A$ participação ativa via chat apresentou um ligeiro aumento nos dois momentos de coleta para ambos os grupos (inicial ingressantes $=4.1$; final ingressantes $=4.2$; inicial veteranos $=4.2$; final veteranos $=4.3$ ); porém, essas alterações não podem ser consideradas expressivas estatisticamente.

Para os dois indicadores, usos e manejos básicos e usos e manejos avançados de Tecnologias Digitais de Informação e Comunicação (TDIC), ressaltamos que a capacidade para a instalação de softwares e para o uso de planilhas eletrônicas, a capacidade de compreensão de tutoriais ou manuais de usuário, a capacidade de aprender por si funções avançadas de um programa ou software específico e a capacidade de utilização de alguma linguagem de programação para desenvolver tarefas acadêmicas foram os itens que apresentam resultados menos satisfatórios na avaliação dos alunos e devem passar por intervenções didáticas mais acentuadas para sua qualificação, dado que são capacidades requeridas para um estudante universitário, independentemente da pandemia, de forma geral. Nenhum dos itens vinculados a esses indicadores apresentou diferença estatística nos dois momentos de coleta de dados.

Para os indicadores de relacionamento com recursos multiformato, ressalta-se que tanto o consumo quanto a produção desses recursos sofreram incremento por parte dos discentes no comparativo dos dois momentos de coleta de dados, especialmente a capacidade para acessar videoaulas relacionadas aos temas acadêmicos e a capacidade de gravar e editar vídeos para trabalhos acadêmicos (pois ambos indicadores, nos dados gerais, além das médias, apresentaram mudanças também nas respectivas medianas, de 4 para 5 no primeiro caso e de 3 para 4 no segundo). Essa diferença foi estatisticamente corroborada pelo teste de Wilcoxon já mencionado anteriormente, sendo esses os únicos itens que apresentaram diferença significativa para todo o conjunto de dados relacionados à autoeficácia.

O último indicador do macro-construto de autoeficácia trazia dois itens relacionados à capacidade pessoal de adaptação ao ensino remoto. O primeiro, textualmente, é constituído pela proposição que se refere à capacidade de "concentrar-se para ler e trabalhar em atividades acadêmicas, esquivandose de distrações e barulhos" (Média inicial e final= 3.4; Mediana=4.0) e o segundo, "adaptar-se plenamente ao uso de qualquer plataforma e/ou recurso para fins acadêmicos" (Média inicial e final= 3.9; Mediana=4.0). Em ambos os casos, as médias e medianas foram idênticas no início e no final, seja para o grupo de ingressantes, seja para o grupo de veteranos.

Feito esse breve panorama para os indicadores de autoeficácia, passamos ao comparativo dos indicadores de expectativas esperadas versus expectativas observadas. Quando observamos os itens atrelados aos indicadores de expectativas cognitivas e expectativas atreladas ao desempenho 
individual, observa-se que as médias de ambos os indicadores são estáveis nos dois momentos de coleta de dados. Ressalta-se que os estudantes mostraram maior expectativa para a compreensão de conceitos básicos do que de conceitos complexos atrelados às disciplinas durante o ensino remoto (expectativas cumpridas nesse ponto). Observou-se, pelo teste de Wilcoxon, uma mudança positiva no que diz respeito à expectativa de obtenção de um bom desempenho nas tarefas nos dois momentos de coleta de dados, de maneira que as expectativas observadas ao final foram estatisticamente superiores às esperadas ao início do semestre.

Já atrelado ao indicador de socialização do conhecimento, o item relativo à exposição de ideias aos colegas sobre os conteúdos e tarefas apresentou diferença significativa entre os dois períodos; entretanto, para os outros dois itens desse indicador, que estão mais relacionados ao debate e à interação e não à exposição, como o anterior, não houve mudanças. Tais aspectos interacionais aparecem entre os mais sensíveis nos dados analisados, pois o item "Eu acredito que no ensino remoto é mais fácil ajudar os colegas e ser ajudado por eles do que no ensino presencial" é o que apresentou a segunda menor média entre todos os itens da escala (Média=2.40, Mediana=2) ao início do semestre remoto e essa posição se manteve ao término do semestre (Média=2.92, Mediana=3), ainda que, pelo teste de Wilcoxon tenha se observado uma mudança significativa entre os dois momentos de coleta.

O outro item que chamou atenção pela diferença significativa encontrada nos dois períodos relacionase ao indicador da presença docente, pois a expectativa em relação ao suporte do professor(a), tanto quanto no ensino presencial, mostrou-se, pelo teste de Wilcoxon, como estatisticamente diferente na comparação entre as expectativas esperadas e observadas. Esse dado se apresenta, assim, de forma positiva para a conjuntura do contexto analisado.

Já no que diz respeito às expectativas autorregulatórias, chama atenção à diferença negativa entre os dados para o seguinte item: "Eu me sinto (ao início)/me senti (ao final) altamente comprometido com meu processo de aprendizagem neste componente". Há diferença da maioria dos itens de todo o questionário, há um decaimento neste item (Média inicial $=4.22 ;$ Média final=4.08). Ainda que as medianas sejas as mesmas (4.00), o teste de Wilcoxon corrobora para a existência de diferença estatística $(p=0.051)$. Um item complementar deste mesmo indicador também apresentou decaimento, reforçando o dado anterior: "Estou disposto a dar o meu melhor (início)/ dei o meu melhor (final) nesta modalidade de ensino remoto" (Média inicial $=4.55$, Mediana inicial=5.00, Média final $=4.12$, Mediana final $=4.00)$. Esse item também apontou diferença estatística no teste de Wilcoxon.

Ainda no escopo das expectativas autorregulatórias, outro item apresentou diferença estatística: "Eu acho que no ensino remoto eu posso (início)/pude (final) aprender no meu próprio ritmo e tempo". Entretanto, em contraste aos dois anteriores, nesse caso, houve um aumento das expectativas esperadas (Média inicial $=2.98$ ) para as observadas (Média final $=3.35$ ) e não o contrário. 0 penúltimo indicador analisado no escopo das expectativas se refere ao comparativo do ensino remoto com o ensino presencial. Em se tratado do indicador que apresentou maior número de itens com diferenças estatísticas dos dados coletados nos dois momentos, optamos por apresentar um quadro completo, também por ser o indicador que revela mais categoricamente a percepção direta dos alunos em relação ao ensino remoto, ao trazer a comparação explícita com o modelo presencial: 
Quadro 2. Detalhamento do indicador comparativo Presencial versus Remoto

\begin{tabular}{|l|l|l|l|l|l|}
\hline \multicolumn{1}{|c|}{ Itens } & $\begin{array}{c}\text { Média } \\
\text { Inicial }\end{array}$ & $\begin{array}{c}\text { Mediana } \\
\text { inicial }\end{array}$ & $\begin{array}{c}\text { Média } \\
\text { final }\end{array}$ & $\begin{array}{c}\text { Mediana } \\
\text { final }\end{array}$ & $\begin{array}{c}\text { valor de } \\
\text { p }\end{array}$ \\
\hline $\begin{array}{l}\text { CERP1 - Eu acredito que onsino remoto } \\
\text { exigirá/exigiu de mim mais esforço do que o } \\
\text { ensino presencial. }\end{array}$ & 4.07 & 4.00 & 3.97 & 4.00 & $\mathrm{p}=0.33$ \\
\hline $\begin{array}{l}\text { CERP2 - Eu acredito que o ensino remoto } \\
\text { exigirá/exigiu de mim mais tempo do que o } \\
\text { ensino presencial. }\end{array}$ & 3.78 & 4.00 & 3.85 & 4.00 & $\mathrm{p}=0.66$ \\
\hline $\begin{array}{l}\text { CERP3- Eu gosto/gostei da ideia de cursar este } \\
\text { semestre de forma remota. }\end{array}$ & 2.88 & 3.00 & 3.27 & 3.00 & $* \mathrm{p}<0.01$ \\
\hline $\begin{array}{l}\text { CERP4 - Eu acho que o processo de } \\
\text { aprendizagem neste componente pode ser/foi } \\
\text { mais fácil no ensino remoto do que se fosse no } \\
\text { ensino presencial. }\end{array}$ & 2.39 & 2.00 & 2.73 & 3.00 & $* \mathrm{p}=0.03$ \\
\hline $\begin{array}{l}\text { CERP5 - Eu acho que pode ser/foi menos } \\
\text { desgastante estudar neste componente por } \\
\text { ensino remoto do que no ensino presencial. }\end{array}$ & 2.66 & 3.00 & 2.88 & 3.00 & $* \mathrm{p}=0.05$ \\
\hline $\begin{array}{l}\text { CERP6 -Eu acredito que a avaliação da minha } \\
\text { aprendizagem no ensino remoto pode ser/foi } \\
\text { equivalente à forma como eu seria avaliado no } \\
\text { ensino presencial (em termos de dificuldade, } \\
\text { rigor, qualidade, etc.), neste componente } \\
\text { curricular. }\end{array}$ & 3.26 & 3.00 & 3.56 & 4.00 & $* \mathrm{p}=0.04$ \\
\hline
\end{tabular}

Fonte: Autoria Própria (2021)

Dos seis itens do indicador, apenas CERP1 e CERP2 não apresentaram diferenças entre as expectativas esperadas e as expectativas observadas (pois o valor de $p$, ou seja, a probabilidade de significância, representada na última coluna a partir do teste de Wilcoxon apresenta valor maior que 0,05 (que é o nível de significância adotado) nesses dois primeiros itens. Vale dizer que esses enunciados são considerados como itens reversos na análise de confiabilidade do instrumento, já que nos demais a comparação é feita em termos de equivalência ao presencial ou, ainda, benefício do modelo remoto. Já todos os itens seguintes (CERP3 até CERP6) podem ser considerados como não idênticos estatisticamente na comparação entre os dois momentos de coleta (com p ou $<0,05$ ). Em nenhum caso identifica-se redução das expectativas, embora tenham sido observados nesse indicador os escores mais baixos de todo o questionário (mais especificamente no item CERP4), nos dois períodos analisados.

O último indicador, relacionado às expectativas ambientais não apresentou nenhuma mudança na comparação entre o início e o fim do semestre. Esse indicador trazia itens que versavam sobre a existência de um ambiente doméstico propício para o estudo, seja em termos de privacidade, seja em local adequado para o estudo remoto. O fato de não haver alteração nesse aspecto se relaciona à inviabilidade de alteração dos espaços domésticos por razões externas e que demandariam algum tipo de investimento financeiro para que pudessem ocorrer, caso o ambiente não fosse adequado. 
Podemos considerar, com base nos dados analisados e em outros trabalhos com focos similares (AGUILERA-HERMIDA, 2020; VADAKALU ELUMALAI et al., 2020; MAYDIANTORO et al., 2020), que as questões mais sensíveis (pelas pontuações geradas), quando se trata de observar a perspectiva dos estudantes sobre o ensino remoto e/ou os elementos tecnológicos que confluem para o desenvolvimento da aprendizagem online, dizem respeito a elementos notadamente atitudinais, emocionais e/ou motivacionais e não exatamente a aspectos técnicos. Podemos citar as principais fragilidades no campo das expectativas autorregulatórias (que evidenciaram decaimento) e, também, os diferentes aspectos abordados no instrumento a respeito de questões interacionais, especialmente no que diz respeito ao engajamento com colegas, o que também aparece na literatura como um aspecto frágil (KNUDSON, 2020).

\section{CONSIDERAÇÕES FINAIS}

A presente pesquisa, ainda que tenha um caráter exploratório focado apenas no primeiro semestre em que a universidade lançou mão do ensino remoto e tenha restringido a coleta a alguns componentes curriculares de graduação, traz elementos relevantes para o planejamento de ações acadêmicas focadas na inserção da tecnologia digital no ambiente universitário, independente da existência do condicionante da pandemia.

Podemos mencionar a presença de questões sensíveis latentes entre os estudantes, tais como: socialização e engajamento entre colegas, necessidade de construção de princípios autorregulatórios e focados na resiliência para a aprendizagem, etc. Também, vislumbra-se a necessidade de estimular os estudantes na adoção de práticas mais complexas de busca de informação para fins acadêmicos e utilização de ferramentas tecnológicas mais avançadas do que comumente utilizam (observa-se que, por exemplo, em comparação com outras práticas mencionadas, a manipulação de planilhas, no manejo básico e a utilização de linguagens de programação, no manejo avançado, apresentaram escores menos expressivos do que outras experiências com a tecnologia digital).

Os dados também revelam a importância de investir no acompanhamento dos ingressantes, já que eles, em geral, tanto nos desempenhos acadêmicos (notas) quanto nas percepções apresentaram escores inferiores aos dos veteranos. No que diz respeito às perspectivas futuras no seguimento de pesquisas dessa natureza, pretendemos refinar o escopo do questionário aplicado, reduzindo o número de indicadores pré-estabelecido. Ainda no que diz respeito aos achados da pesquisa, entendemos que alguns desses resultados (especialmente apresentados nos indicadores focados na interação e engajamento com colegas e nas práticas autorregulatórias) podem trazer possíveis impactos para a adoção de metodologias ativas para as disciplinas em análise, as quais têm como pano de fundo princípios interacionistas fortes, tendo a necessidade de constante manutenção do engajamento com os pares, dentro e fora de sala de aula. Ou seja, uma percepção dos alunos mais conservadora ou individualista sobre tais aspectos pode impactar na efetividade de um desenho metodológico mais inovador por parte dos docentes.

Por fim, entendemos que os dados trouxeram elementos muito mais complexos e profundos do que é possível apresentar em um artigo desta natureza e que tais resultados precisam ser reinterpretados de forma mais abrangente, com foco em desenvolver intervenções que permitam modificar as trajetórias acadêmicas para favorecer o desenvolvimento da autonomia e da aprendizagem profunda, seja em um ecossistema educacional presencial e/ou virtual. Nesse sentido, o ensino remoto foi 
desencadeador de novas reflexões, as quais, possivelmente, não estariam postas caso esse momento disruptivo não tivesse se estabelecido. Para concluir, reforçamos que os dados suscitam novos encaminhamentos formativos necessários na formação dos estudantes, especialmente no que diz respeito a forma como interpretam e vivenciam a mediação tecnológica (na relação com as ferramentas e na relação com as pessoas), a fim de favorecerem e buscarem melhores estratégias para o seu desenvolvimento profissional.

\section{REFERÊNCIAS}

AGUILERA-HERMIDA, Patricia. College students' use and acceptance of emergency online learning due to COVID-19. International Journal of Educational Research Open, [s. I.], v. 1, p. 100011, 2020. Disponível em: https://doi.org/10.1016/j.ijedro.2020.100011. Acesso em: 9 jun. 2021.

ARRUDA, Euclidio. Educação Remota Emergencial: elementos para políticas públicas na educação brasileira em tempos de Covid-19. Revista de Educação a distância Em Rede, v.7, n.1, p.257275, 2020.

BANDURA, Albert. Guide for constructing self-efficacy scales. In: PAJARES, Frank; URDAN, Timothy C. (org.). Self-efficacy beliefs of adolescents. Greenwich, Conn: IAP - Information Age Pub., Inc, 2006. (Adolescence and education). p. 307-337.

BATES, Reid; KHASAWNEH, Samer. Self-efficacy and college students' perceptions and use of online learning systems. Computers in Human Behavior, [s. l.], v. 23, n. 1, p. 175-191, 2007. Disponível em: https://doi.org/10.1016/j.chb.2004.04.004. Acesso em: 9 jun. 2021.

BRASIL. Ministério da Saúde. Portaria n̊ 188, de 03 de fevereiro de 2020. Declara Emergência em Saúde Pública de importância Nacional (ESPIN) em decorrência da Infecção Humana pelo novo Coronavírus (2019-nCoV). Diário Oficial da União: seção 1, edição 24-A, Brasília, DF, p.1, 04 fev. 2020.

BRASIL. Ministério da Educação. Portaria n̊ 343, de 17 de março de 2020. Dispõe sobre a substituição das aulas presenciais por aulas em meios digitais enquanto durar a situação da pandemia do Novo Coranavírus - COVID-19. Diário Oficial da União: seção 1, edição 53, Brasilía, DF, p.39, 18 mar.2020.

CRONBACH, Lee. Coefficient alpha and the internal structure of tests. Psychometrika, v. 16. n. 3, p. 297-334, set. 1951.

INGOLD, Tim. The perception of the environment: essays of livelihood, dwelling and skill. Londres/Nova York: Routledge, 2000.

IRALA; Valesca Brasil et al. Material complementar - Dados brutos do artigo EXPECTATIVA VERSUS REALIDADE: EXPERIÊNCIAS, PERCEPÇÕES E DESEMPENHOS DISCENTES FRENTE AO ENSINO REMOTO. Disponível em: https://docs.google.com/spreadsheets/d/1evDaV4taD17kSnQljmyHor5Tbhg6sn4tDaubNWEBuk/edit\#gid=0. Acesso em: 19 jul. 2021. 2021a.

IRALA; Valesca Brasil et al. Material complementar - Descritivo das análises do artigo EXPECTATIVA VERSUS REALIDADE: EXPERIÊNCIAS, PERCEPÇÕES E DESEMPENHOS DISCENTES FRENTE AO ENSINO REMOTO. Disponível em:

https://docs.google.com/spreadsheets/d/1XxymJYGouC12E0yDs1BYD0iNsIS84yFtaz7OisDPpWY/edit \#gid=167434096. Acesso em: 19 jul. 2021. 2021b.

JOSSO, Mari-Christine. Experiências de vida e formação. Lisboa: Educa, 2002. 
KNUDSON, Duane. A tale of two instructional experiences: student engagement in active learning and emergency remote learning of biomechanics. Sports Biomechanics, [s. I.], p. 1-11, 2020. Disponível em: https://doi.org/10.1080/14763141.2020.1810306. Acesso em: 9 jun. 2021.

LAWSON, Michael J. et al. Teachers' and Students' Belief Systems About the Self-Regulation of Learning. Educational Psychology Review, [s. I.], v. 31, n. 1, p. 223-251, 2019. Disponível em: https://doi.org/10.1007/s10648-018-9453-7. Acesso em: 9 jun. 2021.

LEVIN, Jack; FOX, James; FORDE, David. Estatística para Ciências Humanas. 11. ed. São Paulo: Pearson, 2012.

MAYDIANTORO, Albet et al. (Emergency) Online Remote Learning in Higher Education Institutions during COVID-19 Crisis: Students' Perception of the Situation. Universal Journal of Educational Research, [s. l.], v. 8, n. 12, p. 6445-6463, 2020. Disponível em: https://doi.org/10.13189/ujer.2020.081210. Acesso em: 9 jun. 2021.

MORENO, Luisa Zanolli; MORCILLO, André Moreno. Comparação de dois grupos pareados Teste de Wilcoxon. [s. l.], 2020. Disponível em: https://doi.org/10.13140/RG.2.2.35331.66081. Acesso em: 9 jun. 2021.

NEVES, Vanusa; VALDEGIL, Daniel; SABINO, Raquel. Ensino remoto emergencial durante a pandemia de COVID-19 no Brasil: estado da arte. Práticas Educativas, Memórias e Oralidades - Rev. Pemo, [S. I.], v. 3, n. 2, p. e325271, 2021. DOI: 10.47149/pemo.v3i2.5271. Disponível em: https://revistas.uece.br/index.php/revpemo/article/view/5271. Acesso em: 9 jun. 2021.

PARDO KUKLINSKI, Hugo; COBO, Cristobál. Expandir la universidad más allá de la enseñanza remota de emergencia: ideas hacia un modelo híbrido post-pandemia. Barcelona: Outliers School, 2020.

RAUEN, Fábio. Roteiros de pesquisa. Rio do Sul: Nova Era, 2006.

R CORE TEAM. R: a language and environment for statistical computing. R Foundation for Statistical Computing (Version 4.0), 2021. Disponível em: https://www.R-project.org/. Acesso em: 08 jun. 2021.

SOUZA, Ana Cláudia; ALEXANDRE, Neusa Maria Costa; GUIRARDELLO, Edinêis de Brito. Propriedades psicométricas na avaliação de instrumentos: avaliação da confiabilidade e da validade. Epidemiol. Serv. Saúde, Brasília, v. 26, n.3, p.647-657, jul-set. 2017. DOI: 10.5123/S167949742017000300022.

TINTO, Vincent. Completing college: rethinking institutional action. Chicago: The University of Chicago Press, 2012. 240 p.

THE JAMOVI PROJECT. Jamovi. (Version 1.8), 2021. [Computer Software]. Disponível em: https://www.jamovi.org. Acesso em: 08 jun. 2021.

VAUGHAN, Norman; CLEVELAND-INNES, Martha; GARRISON, Randy. Teaching in blended learning environments: creating and sustaining communities of inquiry. Edmonton: $A U$ Press, 2013. (Issues in distance education series).

VADAKALU ELUMALAI, Kesavan et al. Factors Affecting the Quality of E-Learning During the COVID19 Pandemic from the Perspective of Higher Education Students. Journal of Information

Technology Education: Research, [s. l.], v. 19, p. 731-753, 2020. Disponível em: https://doi.org/10.28945/4628. Acesso em: 9 jun. 2021.

Submissão: 16/06/2021

Aceito: $20 / 07 / 2021$ 